Check for updates

University of Bristol, Bristol, UK

gabriel.scally@btinternet.com

Cite this as: BMJ2021;373:n875

http://dx.doi.org/10.1136/bmj.n875

Published: 01 April 2021

\section{A new public health body for the UK}

\section{"Local first" approach dropped in favour of industrial and security oriented agency Gabriel Scally visiting professor of public health}

The UK government has implemented a far reaching restructuring and reorientation of the country's public health infrastructure with the creation of the UK Health Security Agency (UKHSA). ${ }^{1}$ In the House of Commons on 24 March, the UK prime minister told the nation that holding an inquiry into the handling of the covid-19 pandemic would be an "irresponsible diversion" at the present time. ${ }^{2}$ Nonetheless, on the same day, the government announced the imminent creation of UKHSA, a brand new organisation. ${ }^{3}$

In August 2020, the abolition of Public Health England (PHE), a civil service agency and part of the Department of Health and Social Care, was announced by the government. ${ }^{4}$ At that time, the government stated that PHE was to be replaced by the National Institute for Health Protection. They indicated that they were examining good practice in public health organisations worldwide, explicitly mentioning Germany's Robert Koch Institute. The policy paper on the new institute, published in September 2020, promised a "local first approach" and close working with councils and their directors of public health.

\section{Concerns for public health}

The government's thinking has shifted in a concerning direction since then. The new name for the organisation and short, two page policy paper make clear that the new entity is to be part of the UK's national infrastructure and security system. It also states that UKHSA will have a core function in driving economic growth as an integral part of what politicians term "UK plc." In particular, it is envisaged as "acting as an engine" for the life sciences and diagnostics industry.

A critical weakness of the UK's pandemic response has been the overreliance on technological solutions to the detriment of proved public health interventions-such as quarantine and local find, test, trace, isolate, and support systems. One enduring problem has been the misleadingly named NHS Test and Trace programme. ${ }^{5}$ The UK parliament's Public Accounts Committee has been scathing of both the enormous cost of this system, designed and operated by the private sector, and its lack of effectiveness.

The emergence of a powerful medical-industrial complex was first described in the US in the 1960 s. $^{6}$ In the UK, the influence of this sector of the economy increased after 2010 as it took advantage of the contracting of core NHS services to the private sector. In its pandemic response, the government pivoted away from public health and NHS functions and organisations. Taking advantage of the emergency to dispense with normal tendering and contracting procedures, funding on a colossal scale was passed to the private sector. Similarly, in data analytics, the government has engaged state security organisations and the private sector to provide crucial information on covid-19. ${ }^{7}$ Against this background, it is likely that the creation of UKHSA will be seen by many as a further step in the growth of a centralised and secretive state apparatus with the close engagement of private sector interests.

The development of a powerful health security organisation under direct ministerial control will also be in keeping with the libertarian political view that regards anything to do with promoting public health as an act of the "nanny state" and an assault on the freedoms of business and individuals. A UKHSA focused away from important problems-such as non-communicable disease and the stalled improvement in life expectancy-and towards the perceived external threat to the country of novel infectious diseases, can only further weaken the response to the poor overall health status of the UK. Although health is, in principle, a devolved function, there is little to distinguish the responses to the pandemic seen in the four parts of the UK. However, the creation of UKHSA as a more powerful industrial and security oriented replacement for PHE may not be welcome in the devolved administrations, particularly as the policy paper makes clear it will lead and co-ordinate across the UK and will operate on behalf of the UK internationally.

\section{Distraction}

Over the past decade, the local public health workforce, from school nurses to public health trainees and consultants, has been grossly under-resourced, and the directors of public health in England marginalised. The successful development and deployment of effective vaccines have taken time and, during that period, enormous damage has been done to the health of the population and the economy of the country. Although vaccines will undoubtedly help control the pandemic, a continuing and strengthened community based public health response to covid-19 at a local level is needed. A rushed and profoundly flawed restructuring of a large part of the public health system without consultation or discussion is an unhelpful and ideologically driven distraction.

Department of Health and Social Care. Press release: new UK health security agency to lead response to future health threats. 24 March 2021 www.gov.uk/government/news/new-uk-health-security-agency-to-leadresponse-to-future-health-threats

Johnson B. Hansard HC Deb. House of Commons official report (Hansard) Vol. 691. 24 March 2021:col 915. https://hansard. parliament.uk.

HM Government. Securing our health: the UK Health Security Agency. 24 March 2021. www.gov.uk/government/publications/securing-our-healththe-uk-health-security-agency/securing-our-health-the-uk-health-securityagency. 
4 Scally G. The demise of Public Health England. BMJ2020;370:m3263. doi: 10.1136/bmj.m3263 pmid: 32816779

5 Wise J. Covid-19: NHS Test and Trace made no difference to the pandemic, says report. BMJ 2021;372:n663. doi: 10.1136/bmj.n663 pmid: 33687919

6 Ehrenreich B, Ehrenreich J. The big business of health. Health Policy Advisory Center Bulletin 1969. www.healthpacbulletin.org/CompleteBulletinRun/Health\%2OPAC\%2OBulletin\%201969\%20Nov.pdf.

7 Warrell H, Neville S. Senior spy appointed to lead UK's joint biosecurity centre. Financial Times 5 June 2020. www.ft.com/content/5f65b65e-a7c2-4745-8ad8-fd7a3ec6e0bd. 